\title{
Ist Sport wirklich gesund?
}

\section{Die Mortalität früherer Teilnehmer an Olympischen Spielen liegt bei Sport- arten mit intensiver kardiovaskulärer Belastung nicht niedriger als bei Ath- leten mit niedriger Belastung. Sport- ler mit einem hohen Grad an phy- sischem Kontakt haben im späteren Leben sogar eine höhere Mortalität.}

- Wegen der nachgewiesenermaßen günstigen Einflüsse auf die Prävalenz kardiovaskulärer Erkrankungen, die Mortalität und die Stimmungslage wird heute von allen Experten sportliche Betätigung breiter Bevölkerungsschichten empfohlen. Man kann es freilich auch übertreiben. Dies erfuhr nicht nur Pheidippides, der 490 v. Chr. von Marathon nach Athen lief, um den Sieg der Griechen über die Perser zu verkünden, danach aber umgehend sein Leben aushauchte. Nicht zuletzt deshalb beschlossen die Organisatoren der ersten Olympischen Spiele 1896, den Marathonlauf nach Athen etwas zu verkürzen.

Die heute etablierte Strecke von $42,195 \mathrm{~km}$ geht freilich auf einen Wunsch des englischen Königshauses zurück. Bei den dritten Olympischen Spielen in London sollte der Lauf beim Schloss Windsor beginnen und vor der königlichen Tribüne im White City Stadium enden.

Ob Sport unter den damaligen Bedingungen wirklich einen Einfluss auf die Sterblichkeit hatte, wurde nun in einer retrospektiven Kohortenstudie an 9889 Athleten der Jahrgänge 1830-1910 untersucht, die an den Olympischen Spielen zwischen 1896 und 1936 in 43 verschiedenen Disziplinen teilgenommen hatten und von denen man das Sterbealter kannte. Mit einer Hazard ratio von 1,01 bzw. 0,98 wiesen Athleten mit mäßiger bzw. hoher kardiovaskulärer Belastung in ihren Sportarten die gleiche Mortalität auf wie Athleten mit niedriger Belastung. Eine leicht erhöhte Mortalität stellte man dagegen bei Sportlern fest, deren Disziplin mit einem hohen Risiko für Körperkontakt (HR 1,11) bzw. einem immanenten ho-

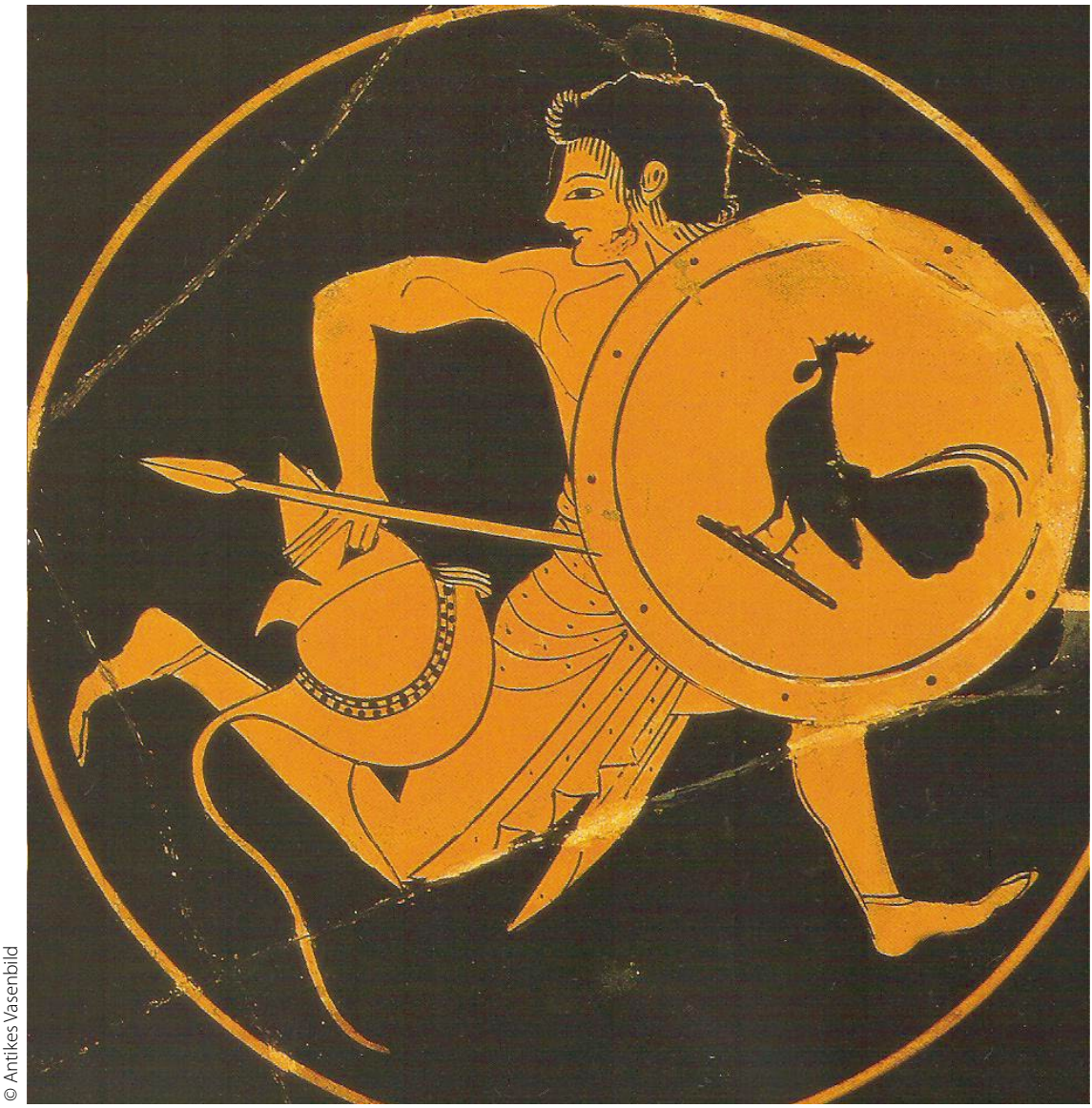

Im Ziel verstorben: Pheidippides, der erste Marathonläufer. Ob es an der eher unpraktischen Ausrüstung lag?

hen Grad des Körperkontakts (HR 1,16) einherging.

Unter den damaligen Bedingungen hatte die kardiovaskuläre Belastung bei den Sportlern früherer Tage offensichtlich keinen entscheidenden Einfluss auf die allgemeine Sterblichkeit. Ob das heute der Fall ist, wird die Zukunft erweisen. Die modernen Trainingsmethoden und die vielfältigen Anwendungen leistungssteigender Mittel lassen befürchten, dass das Gegenteil der Fall sein wird.

\section{Kommentar}

Beim Tod von Pheidippides sollte man allerdings nicht vergessen, dass er nicht nur von Marathon nach Athen gelaufen ist, sondern auch die Schlacht hinter sich hatte, aus der er möglicherweise verletzt davonkam. Vielleicht steht sein Tod mehr im Zusammenhang damit als mit dem legendären Marathonlauf.

\section{- R. Zwiers et al.}

(Korres.: engelaer@leydenacademy.nl): Mortality in former Olympic athletes: retrospective cohort analysis. DMJ 2012; 345: e7456 